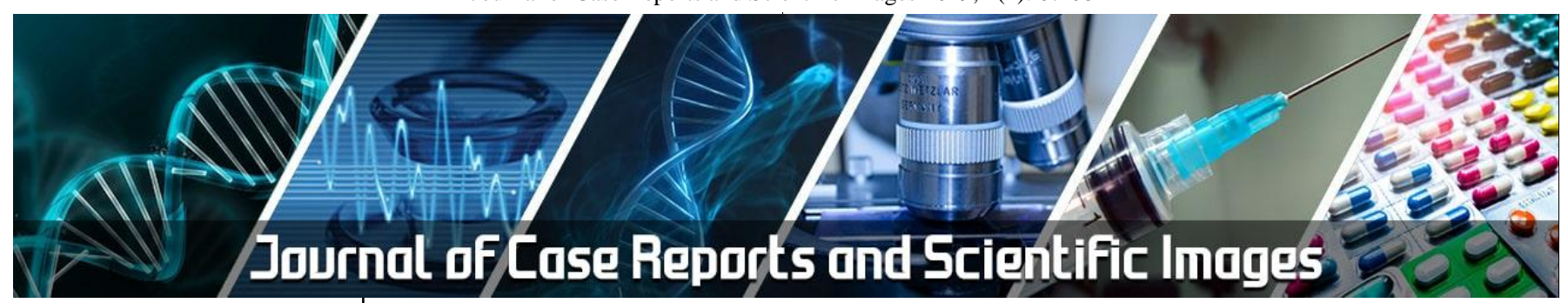

E-ISSN: 2708-0064 P-ISSN: 2708-0056 www.allcasereports.com JCRSI 2019; 1(1): 07-08 Received: 13-11-2018 Accepted: 15-12-2018

Dr. Saeed Shoja Shafti Department of Scientific, Shahjalal University of Science and Technology, Sylhet, Bangladesh
Corresponding Author: Dr. Saeed Shoja Shafti Department of Scientific, Shahjalal University of Science and Technology, Sylhet, Bangladesh

\section{A case of middle ear adenoma in 31 years old male patient}

\section{Dr. Saeed Shoja Shafti}

DOI: https://doi.org/10.33545/27080056.2019.v1.i1a.4

\begin{abstract}
Middle ear glandular tumors are extremely rare and, despite numerous histological techniques, continue to defy satisfactory classification. We reported a case of middle ear adenoma in 31 years old male patient.
\end{abstract}

Keywords: middle ear, glandular tumors, adenoma

\section{Introduction}

Middle ear glandular tumors are extremely rare and, despite numerous histological techniques, continue to defy satisfactory classification. Their cell line of origin, natural history, and progression if left untreated are unknown. Patients generally present with conductive hearing loss and most surgeons advocate surgical excision with or without immediate or delayed reconstruction of hearing ${ }^{[1]}$.

Middle ear adenoma, a very rare type of middle ear tumor, was first reported by Hyams and Michaels) in 1976. Murphy, et al renamed it as carcinoid tumor which is similar to adenoma but is composed of neuroendocrine cells, and as seen on microscopic findings in 1980. Since then it has been called middle ear carcinoid tumor or middle ear adenoma ${ }^{[2]}$.

As middle ear tumors with glandular structure can differentiate to neuroendocrine cells and epithelial cells, middle ear carcinoid tumor and adenoma were initially classified as different tumors, although they are currently considered by the majority of researchers to be the same low-grade middle ear tumor. There is no clear definition regarding the derivation of the two tumors, although middle ear adenoma is divided into middle ear carcinoid tumor and middle ear adenoma ${ }^{[3]}$.

Hypotheses such as the development of middle ear adenoma from the epithelial layer of the middle ear mucous gland and pluripotent endodermal stem cells located in the mucosa during the development of middle-ear-like pulmonary carcinoid tumor arising from Kulchitsky cells ${ }^{[4]}$. We reported a case of middle ear adenoma in 31 years old male patient.

\section{Case Report}

A 31 years old male patient reported to the department with complaint of loss of hearing and pressure sensation in the right ear since two months. The patient reported no pain, otorrhoea, dizziness, or systemic signs of infection.

Otoscopy showed an intact eardrum but with white mass behind the eardrum in the posterior superior/inferior quadrants. A pure tone audiogram showed normal hearing in the left ear, with a high frequency sensorineural loss in the right. Computer tomography showed a right sided middle ear soft tissue mass with possible erosion of the ossicles. The MRI showed a 3 $\times 8 \mathrm{~mm}$ soft tissue mass, isointense on T1 and T2 sequences, with inhomogeneous gadolinium contrast uptake in the meso- and hypotympanum. We planned mastoidectomy, epitympanectomy, and tympanoplasty. Intraoperatively, the whole middle ear was filled with the soft tissue mass apart from a small area superiorly/anteriorly. The chorda tympani had to be sacrificed along with an epitympanectomy to allow adequate visualization and excision of the mass. The tissue was sent to histopathology which showed glandular and neuroendocrine tumor with areas of pleomorphic nuclei. No signs of persistence or recurrence were found. The prognosis was good. 


\section{Discussion}

According to the cases which have been reported up to now, the mean onset age of middle ear adenoma is 44.6 years of age with a male to female ratio of 1.3: 1 in favor of males, and there was no difference between the right and the left ears. In some cases, symptoms of aural fullness, ear pain, otorrhea, tinnitus, dizziness, and facial paralysis were reported ${ }^{[5]}$. According to otoscopic findings, most of the cases showed a normal external auditory canal and eardrum. In the temporal bone CT findings, a soft tissue density surrounding ossicles and a relatively clear margin was observed. MRI was performed for patients who were suspected of having a malignant tumor. The MRI findings showed higher signal of tumor than the white matter in the $\mathrm{T} 1$ sequence, the same signal as the gray matter in the T2 sequence, and an enhancing mass in the gadoliniumenhanced T1 sequence ${ }^{[6]}$. We reported a case of middle ear adenoma in 31 years old male patient.

Shim et al. ${ }^{[7]}$ reported a case in a 17-year-old male who presented with a history of recurrent, bloody otorrhea and high-pitched tinnitus. They diagnosed him with congenital cholesteatoma and performed surgery to remove the entire tumor as well as the incus. However, on postoperative pathology examination, they finally diagnosed the tumor as middle-ear adenoma with neuroendocrine differentiation. In the two years following surgery, the patient's adenoma has not recurred, although long-term observation was required.

The differential diagnosis of middle ear adenoma includes inflammatory diseases such as cholesteatoma and chronic otitis media, and primary middle ear tumor such as ceruminoma, pleomorphic adenoma, paraganglioma, jugular body tumor, and metastatic cancer. For the differential diagnosis, immunohistochemistry is usually performed ${ }^{[8]}$.

Saliba and Evrard ${ }^{93}$ performed a thorough analysis of the literature and proposed a 3-tier classification according to immunohistochemistry $(+/-)$ and metastasis $(+/-)$. When both are negative, the tumor is described as an MEA. The most common type however shows positive immunohistochemistry and no metastasis and is described as a neuroendocrine adenoma of the middle ear. The rarest finding is of a tumor with both positive immunohistochemistry and metastasis/carcinoid syndrome and is described as a carcinoid tumor of the middle ear. Of note, this papermentions an average disease free interval of 53 months, but it is not clear how many patients had aggressive initial treatment, or indeed, how many actually had recurrence.

Lella et al. ${ }^{[10]}$ reported a case in 48-year old man presented at otorhinolaryngology department with a 3-month history of right hearing loss, tinnitus and aural fullness. The otoscopy revealed a gray-white nonpulsatile poster superior retro tympanic mass with intact tympanic membrane. It came to be middle ear adenoma.

\section{Conclusion}

Authors found that Middle ear glandular neoplasms are rare tumors of the middle ear. The case was reported carefully and successful management was done.

\section{References}

1. Wassef M, Kanavaros P, Polivka M, Nemeth J, Monteil JP, Frachet B et al. Middle ear adenoma. A tumor displaying mucinous and neuroendocrine differentiation. Am J Surg Pathol. 1989; 13:838-47.
2. Amble FR, Harner SG, Weiland LH, McDonald TJ, Facer GW. Middle ear adenoma and adenocarcinoma. Otolaryngol Head Neck Surg. 1993; 109:871-6.

3. Angouridakis N, Hytiroglou P, Markou K, Bouzakis A, Vital V. Middle ear adenoma/carcinoid tumour: a case report and review of the literature. Rev Laryngol Otol Rhinol (Bord) 2009; 130:199-202.

4. Tabuchi K, Aoyagi Y, Uemaetomari I, Tobita T, Wada $\mathrm{T}$, Inadome $\mathrm{Y}$, et al. Carcinoid tumours of the middle ear. J Otolaryngol Head Neck Surg. 2009; 38:E91-4.

5. Maintz D, Stupp C, Krueger K, Wustrow J, Lackner K. MRI and CT of adenomatous tumours of the middle ear. Neuroradiology. 2001; 43:58-61.

6. Berns S, Pearl G. Middle ear adenoma. Arch Pathol Lab Med. 2006; 130:1067-9.

7. Shim MJ, Song CI, Yoon TH. A case of middle ear adenoma. Korean journal of audiology. 2012; 16(1):27.

8. Saliba, Evrard AS. Middle ear glandular neoplasms: adenoma, carcinoma or adenoma with neuroendocrine differentiation: A case series. Cases Journal. 2009; 2:6508.

9. McNutt MA, Bolen JW. Adenomatous tumor of the middle ear. An ultrastructural and immunocytochemical study. Am J Clin Pathol. 1985; 84:541-7.

10. Lella FA, Nabi BN. Middle Ear Adenoma: A Rare Location for a Benign Tumor. J Otolaryngol ENT Res. 2017; 7(1):00188. 